\title{
Kırgızistan'da orta öğretim edebiyat kitaplarında millî bilinç
}

\section{Akartürk KARAHAN1}

\section{Sibel BARCIN ${ }^{2}$}

\begin{abstract}
APA: Karahan, A.; Barcın, S. (2020). Kırgızistan'da orta öğretim edebiyat kitaplarında millî bilinç.
\end{abstract} RumeliDE Dil ve Edebiyat Araştırmaları Dergisi, (Ö7), 39-44. DOI: 10.2900o/rumelide.808202.

\section{$\ddot{O} \mathbf{z}$}

Dil; bir milletin varlığını sürdürme, kültürünü aktarma yollarından biridir. Dil aracılığıyla insanlar doğru iletişimi sağlar, ulus bilincini, maddi ve manevi kültür ögelerini, değerlerini öğrenirler. Millî bilincin bir ülke içerisinde varlığını sürdürmesinde devletin dil, kültür, tarih, eğitim ile ilgili politikaları etkilidir. Millî politikaların uygulanması ülkeden ülkeye, yönetimden yönetime değişim gösterir. Kırgızistan'daki dil, kültür, edebiyat, tarih eğitimini içine alan millî planlamalar, SSCB dönemi ve bağımsızlık sonrası olarak değişim gösterir. Bu çalışmada, bağımsızlık sonrası Kırgız millı̂ bilincinin okul ders kitaplarında uygulanması araştırılmıştır. Bu kapsamda orta öğretim (10. ve 11. sınıflar) Kırgız edebiyatı kitapları ele alınmıştır. Çalışmada Kırgız dilinin ve edebiyatının öğretimindeki genel sorunlarını tespit etmek, Kırgız halkının kültürünü, gelenek ve göreneklerini Kırgız edebiyatı ders kitaplarına ne kadar yansıtıldığını gözlemlemek, ilgili alanyazında Kırgız millî bilincinin inşasında devletin eğitim politikalarını göstermek amaçlanmıştır. Çalışmaya yönelik bulgular doküman incelemesi yöntemiyle toplanmıştır. Kırgızistan'daki 10. sınıf Kırgız edebiyatı ders kitabı için Keñeşbek Asanaliyev, Sovetbek Baygaziyev, Salican Cigitov, Kireşe İmanaliyev, Kırgız Adabiyatı, 1O- Klass (2003); 11. sınıf Kırgız edebiyatı için, K. Artıkbayev, K. Asanaliyev, S. Baygaziyev, K. İmanaliyev, N. İşekeyev ve A. Muratov, Kırgız Adabiyatı, 11- Klass (2013) kitapları esas alınmıştır. Orta öğretim Kırgız edebiyatı ders kitaplarının 2018 yılı Kırgız Edebiyatı Programı ile tutarlı olduğu ve öğrencilerde millî bilinç oluşturmada başarılı olduğu gözlenmiştir.

Anahtar kelimeler: Kırgız edebiyatı, Kırgız dili, millî bilinç, millî kimlik

\section{National consciousness in secondary education literature books in Kyrgyzstan}

\begin{abstract}
Language is one of the ways of maintaining a nation's existence and keeping it's culture. By the means of language people provide the right communication, they can understand national consciousness, material and spiritual elements of culture. The policies of the state regarding language, culture, history and education are effective in maintaining the existence of national consciousness in a country. The implementation of national policies varies from country to country, from administration to administration. National planning, which includes language, culture, literature and history education in Kyrgyzstan, differs from the period of the USSR and after the independence. This study researches the application of post-independence Kyrgyz national consciousness in school textbooks. In this context, secondary education (10th and 11th grades)
\end{abstract}

1 Doç. Dr., Ankara Yıldırım Beyazıt Üniversitesi, İnsan ve Toplum Bilimleri Fakültesi, Türk Dili ve Edebiyatı Bölümü (Ankara, Türkiye), akartrk@yahoo.com, ORCID ID: 00oo-0002-9117-6356 [Makale kayıt tarihi: 06.06.2020-kabul tarihi: 20.10.2020; DOI: 10.29000/rumelide.808202]

2 Dr. (Türkçe okutmanı), Kırgızistan-Türkiye Manas Üniversitesi, Yabancı Diller Yüksek Okulu (Bişkek, Kırgızistan), sibel.barcin@manas.edu.kg, ORCID ID: oooo-0002-7617-2699 
Kyrgyz literature books were discussed. In this study, the application of post-independence Kyrgyz national consciousness in school textbooks was investigated. The goal of the study is to find the main problems in teaching the Kyrgyz language and literature, to find out how deep the customs of Kyrgyz people are presented in those textbooks and to show the educational policies of the state in the construction of Kyrgyz national awareness in the relevant literature. Materials for the study were collected by the method of document analysis. For the 1oth grade Kyrgyz literature textbook in Kyrgyzstan, Keñeşbek Asanaliyev, Sovetbek Baygaziyev, Salican Cigitov, Kireşe İmanaliyev, Kırgız Adabiyatı, 1O- Klass (2003); for 11th grade Kyrgyz literature, K. Artıkbayev, K. Asanaliyev, S. Baygaziyev, K. İmanaliyev, N. İşekeyev ve A. Muratov, Kırgız Adabiyatı, 11- Klass (2013) books are taken as a basis. It has been observed that secondary education Kyrgyz literature textbooks are consistent with the 2018 Kyrgyz Literature Program and are successful in creating national consciousness among students.

Keywords: Kyrgyz literature, Kyrgyz language, national consciousness, national identity.

\section{Giriş}

Bir milleti, devleti ve toplumu ortak millî değerler ve bireylerdeki millî bilinç bir arada tutmaktadır. Ortak millî değerlerin bir toplumda kuvvetli oluşu o toplumu güçlü kılarken millî değerlerin zayıflığı toplumsal bağları zayıflatmaktadır. İnsanların bireysel, statü, eğitim vb. farklılıklarına rağmen ortak değerlerde, ortak bir bilinç oluşturmasıyla devletler birçok alanda başarılı olur. Ekonomide, sanatta, siyasette, eğitimde başarılı olan ülkelerin toplumsal yapılarına bakıldığında millı̂ bilincin, ortak değer yargılarının güçlü olduğu görülür. Bu nedenle devletler eğitim politikası olarak ilk olarak devlet, ülke, bayrak, vatan, millet, dil, din gibi kavramlar bağlamında millî bilincin gelişmesine çalışır. Eğitim politikaları devletlerin temel değer yargılarını yeni nesillere kazandırma çerçevesinde hazırlanır. Temel değerlerin ve bilincin oluşturulmasında eğitimin her aşamasında/sınıfında ve okulların her dersinde gerekli programlar yapılır. Bununla birlikte dil ve edebiyat dersleri millî bilincin sağlamlaştırılmasında diğer derslerden daha fazla katkı sağlar. Dil ve edebiyat derslerindeki müfredatlar ana dili sevgisini aşılamada ve toplumda dil birlikteliğini sağlamada önemlidir.

Kırgızistan bă̆ımsızlığını 1991'de kazandıktan sonra kendi dil ve eğitim politikalarını geliştirmiş, Sovyet döneminden farklı bir planlamaya gitmiştir. Kırgızistan'da tarihi ve kültürel miras devlet tarafından anayasal güvenceye alınmıştır. Kırgızistan'da Kırgızların yanı sıra çok sayıda Türk ve yabancı etnik unsur bulunmaktadır. 22 Ocak 1994’te “Kırgızstan Elinin Assambleyası” adında farklı etnik unsurların birlik içinde yaşaması amacıyla bir kurum oluşturulmuştur. Kırgızistan'da bağımsızlıktan sonraki dönemde çok kültürlü yapının içerisinde ulus devlet inşası için Kırgız diline ve edebiyatına eğitimde önem verilmiştir. Eğitim müfredatında dil, edebiyat ve tarih konularına ağırlık verilmiştir.

Bu çalışmada Kırgızistan'daki ortaöğretim (lise 10. ve 11. sınıflar) dil ve edebiyat ders kitaplarındaki millî bilinç konusu ele alınmıştır. Millî değerler bu derslerin programlarında ne şekilde yer almış ve ne derece ders kitaplarında bu değerlerin aktarımı başarılmıştır? sorusuna yanıt aranmıştır.

Eski Sovyet coğrafyasında ortaya çıan yeni cumhuriyetlerde dil, devletlerin bağımsızlıklarında son derece önemli bir olgu olarak görülmüştür. Büyük ölçüde devletin hayatta kalma meselesi olarak değerlendirilen dil konusu, yeni cumhuriyetlerin kimliklerinin korunmasından çok, inşa edilmesi açısından önemli görülmektedir. Ancak bununla birlikte Orta Asya Türk Cumhuriyetlerinde 70 yılı 
aşkın bir süredir etkinliğini sürdüren Rusçanın etkisi yadsınamaz bir gerçektir. Kırgızistan'daki Kırgızlar ve diğer milletlerin ana dillerinin yanı sıra Rusça en önemli iletişim aracı konumunda olmuştur. Bu yönüyle Rusça gerek Kırgızistan'da gerekse diğer bağımsız Türk cumhuriyetlerinde ortak bir iletişim ve yazı dili (lingua franca) görevini görmektedir. Rus dilinin bu derece sağlam ve güçlü bir şekilde yaşaması, Kırgızistan ve diğer bağımsız devletlerde kendi dillerinin devlet dili olmasında, buna bağlı olarak millî bilincin kurulmasında bazı zorlukları beraberinde getirmiştir (Abdıeva 2017: 187).

Dil ve edebiyat eğitimi ve öğretiminin başarılı olması, toplumdaki bireylerin hem sağlıklı iletişim kurabilmelerini hem de ortak değerlerde birleşmelerini sağlar. Bu nedenle öğrencilerin ana dilini doğru ve amacına uygun bir şekilde kullanabilmeleri için ders kitaplarındaki metinlerin titizlikle seçilmesi, devletin millî eğitim politikalarına uygun hazırlanması önemlidir (Açık, Önkaş ve Günay, 2015: 366). Kırgızistan'a bağımsızlık ile birlikte pek çok yenilik gelmiştir. Bu durum eğitim alanında da gerçekleşmiştir. Kırgızistan, eğitim politikasını millî ideoloji ve millî değerlere dayandırmıştır. Bu yeni politika çerçevesinde yeni ders müfredatları oluşturulmuş ve bağımsızlıktan sonra ülkenin millî ideolojisine dayanan ders kitapları hazırlanarak yayımlanmıştır (Akimcan Kızı 2008: 1).

Edebiyat; öğrencinin gelişimini etkileyen, bir metinde geçen çeşitli karakterler yoluyla ona yön veren, kendi kültürüyle yoğrulmasını sağlayan ve farklı kültürlerin dünyasıyla tanıştıran bir hazinedir. $\mathrm{Bu}$ nedenle metin seçimine büyük önem verilmeli, ders kitaplarındaki metinlerin devletin temel değerleriyle uyumlu olması, milletin tarih ve kültüründen bağımsız olmaması gereklidir. Eğitimciler de edebiyat metinlerini bu bakımdan ön planda tutar: "Edebiyat ve dil öğretimi denildiğinde, metinler ve bunların seçimi akla gelir. Zira gerek öğretim programları gerekse ders kitapları için metin seçimi, üzerinde önemle durulması gereken bir konudur. Edebiyat ve dil öğretiminde metin seçiminin önemi sık sık vurgulanmıştır.” (Eskimen 2016: 40)

Her edebî eserde, anlatılmak istenen bir mesaj vardır. Bu mesaj yerine göre tarihî, dinî, ahlâkî, sosyal, ekonomik ve kültürel olabilir (Aytaş, 2006: 262). Edebî eserlerin verdikleri mesajların millî değerlerle ters düşmemesi, millı̂ bilinç kavramını pekiştirici olması, eğitimdeki temel hedeflerden birisidir.

\section{Çalışmanın amacı}

$\mathrm{Bu}$ çalışmanın amacı Kırgızistan'daki lise edebiyat kitaplarını millî bilinç açısından incelemek ve yeterlikleri ile eksikliklerini değerlendirmektir. Bu amaç doğrultusunda aşağıdaki sorulara yanıt aranmıştır:

1. Kırgızistan'da ulusal kimliğin kalıcılığı için ne tür çalışmalar yapılmıştır?

2. Edebiyat kitapları, Kırgız edebiyatı programları ile tutarlı mıdır?

3. Kırgız edebiyatının temel amaçları beklenen hedef davranışları karşılıyor mu?

\section{Çalışmanın yöntemi}

$\mathrm{Bu}$ çalışma, nitel araştırma yöntemi olan doküman analizi ile toplanmıştır. Doküman analizi araştırılan olgu veya olgular hakkında bilgi içeren yazılı materyallerin analizini kapsar. Eğitimle ilgili araştırmalarda müfredat programları, okul içi ve okul dışı yazışmalar, toplantı tutanakları, ders kitapları, öğrenci kayıtları, öğretmen ve öğrenci el kitapları, ders ve ünite planları vb. dokümanlar kullanılabilir (Yıldırım-Şimşek 2006: 187). 
$\mathrm{Bu}$ çalışmada doküman analizi olarak 2018 10-11. Sınıflar İçin Kırgız Edebiyatı Standardı incelenmiştir. Kırgızistan'daki 10. sınıf Kırgız edebiyatı ders kitabı için Keñeşbek Asanaliyev, Sovetbek Baygaziyev, Salican Cigitov ve Kireşe İmanaliyev'in 2003'te yayımlanan “Kırgız Adabiyatı, 10- Klass”; 11. sınıf Kırgız edebiyatı için K. Artıkbayev, K. Asanaliyev, S. Baygaziyev, K. İmanaliyev, N. İşekeyev ve A. Muratov'un 2013’te yayımlanan “Kırgız Adabiyatı, 11- Klass” değerlendirilmiştir.

\section{Sinurlılıklar}

Bu çalışma, öğretim dili Kırgız Türkçesi olan eğitim kurumlarında okutulan orta öğretim Kırgız edebiyatı ders kitapları ile sınırlıdır.

\section{Bulgu ve yorumlar}

2018 10-11. Sınıflar İçin Kırgız Edebiyatı Standardını hazırlayanlar değer ve kültür aktarımına çok önem vermektedir. Bir arada yaşayan bir çok etnik grubun kendilerine özgü belirli değer ve kültür algıları vardır. Farklı değer yargılarının ötesinde bir üst millî bilincin olması, ortak dil, kültür ve devlet anlayışı ne kadar pekişirse o kadar birlik ve bütünlük artar. Bu sebeple Kırgızistan'da devletin üst yetkilileri çok kültürlülüğe önem vermiş ve Kırgız Türkçesini Kırgızistan'da yaşayan vatandaşlar arasında ortak iletişim dili olarak kullanılmasını desteklemişlerdir.

Kırgız edebiyatı ders kitapları görsel araçlar bakımından incelendiğinde görsel araçların yeterli düzeyde olmadığı gözlenmiştir. Edebiyatçıların hayatı tanıtılırken şair ve yazarın fotoğrafı eklenmiştir. Ayrıca ders kitaplarının kapaklarına Kırgız halkına özgü motifler yerleştirilmiştir. Ancak öğrencinin okumaya daha çok dikkatini çekmek için karikatür, resim vb. görsel araçlardan yeterince faydalanılmamıştır.

Edebiyat kitapları konu bakımından ele alındığında 10. sınıf Kırgız edebiyatı ders kitabında sosyal hayat, iletişim, temel hak ve özgürlükler, Kırgızların efsanevi kuşu Buudayık, eski-yeni zaman karşılaştırılması, kaygı, özlem, üzüntü, korku, iyilikseverlik, sevgi, medeniyet, kültürel farklılıklar, boylar arası iletişim, birlik ve beraberlik, dayanışma, zaman, iyilik ve kötülük, insanlarla iletişim, çalışkanlık, beceri, akıl, canlılar, doğa, hasret, Kırgız halk kahramanı Şabdan, cesaret, kahramanlık, yenilikçi düşünme, vatanseverlik, eşitlik, çalışkanlık, tarih, kahramanlık, fedakârlık, millî mücadele, Rus-Kazak askerleriyle savaş mücadelesi, halkın savaşı kaybetmesi ve milletin Isık-Göl ile vedalaşması, Kırgızların işkence altında kalması, boylar arasındaki savaş mücadelesi ve kahraman Balbay'ın iç ve dış düşmanlar ile olan mücadelesi işlenmiştir. 11. sınıf Kırgız edebiyatı ders kitabında kader, toplumsal kurallar, dayanışma, gelenekler, aile, evlilik, ahlak, sabır, sevgi, iletişim, dede-çocuk iletişimi, dayanışma, balıkçılık, dayanışma, ölüm, sadakat, duygu değişimi, Abay, adalet, yetenek, vatanseverlik, bireysel farklılıklar, iletişim vb. konular okuma metinlerinde yer almıştır. Edebiyat kitaplarında işlenen konulardan görüleceği üzere, ders kitaplarında millî bilinci oluşturmak ve geliştirmek adına toplumsal, siyasi ve tarihî alanlarda öğrencinin bilgilendirildiği görülmektedir.

Ders kitaplarındaki değerlere bakıldı̆̆ında öğrencilere Kırgız halkına özgü değerler ile birlikte evrensel değerler de kazandırılmaya çalışılmıştır. Okuma metinlerinde iyilikseverlik, uyum, güvenlik, gelenek, evrensellik, güç ve başarı değerleri dikkat çekmektedir. Ayrıca öğrenciye yardımsever olma, arkadaşlık, geleneklere saygılı olma, sevdiklerine değer verme, aile güvenliği, toplumsal düzenin sürmesi, toplumsal adalet, eşitlik, doğayla bütünlük içinde olma, başarılı olma erdemlerini kazandırmak amaçlanmıştır. 


\section{Sonuç}

Toplumda millî bilincin oluşmasında en önemli unsurlardan biri olan dil, eğitim sisteminde de önemli bir yere sahiptir. Devlet dili olarak Kırgız Türkçesinin geliştirilmesi adına "2014-2020 Kırgız Cumhuriyetinde Devlet Dili ve Dil Politikasının Geliştirilmesi Ulusal Programı” yayımlanmıştır. Bu Program'da eğitim, bilim, dil öğretimi, kültür, televizyon ve radyo yayıncılı̆̆ gibi alanlardaki dil politikalarına yer verilmiştir. Bu bilgilerden hareketle devlet yetkililerinin Kırgız Türkçesini korumak ve geliştirmek için çalıştığı ve önemli adımlar attığı görülmektedir.

2018 10-11. Sinıflar İçin Kırgız Edebiyatı Standardında edebiyat öğretiminin sadece dil unsurlarını öğretme ya da edebî metin okuma alışkanlığı kazandırma olmadığı, dilin kültür yönünün de önemli olduğu aktarılmıştır. Ancak Kırgız Edebiyatı Standardında Türk edebiyatından herhangi bir edebiyatçı yer almamıştır. Millı̂ bilinç, dar anlamda "Kırgız millı̂ bilinci” şeklinde kabul edilmiş, geniş anlamda "Türk millı̂ bilinci”ne eğitim programlarında yer verilmemiştir. Buna karşın Türkiye Cumhuriyeti Milli Eğitim Bakanlığı "Türkçe Dersi Öğretim Programında” (2018: 19) "Ders kitaplarına alanda yaygın olarak kabul görmüş yazar ve eserlerden, edebî ve kültürel değer taşıyan metinler alınmalıdır. Türk cumhuriyetleri ve Balkan Türkleri edebiyatlarından eserlere yer verilmelidir.” ibaresi bulunmaktadır. Türkiye'deki programda "millî bilinç" Türkiye Cumhuriyeti vatandaşı olma değeri yanı sıra geniş anlamda Balkanlar, Kıbrıs, Orta Asya vd. Türk topluluklarını da içine alan bir değer taşımaktadır. Kırgızistan'daki eğitim programlarında ise "Kırgız" millî bilinci başlı başına bir millı̂ değer olarak görünmektedir. Bu nedenle Kırgızistan ders kitaplarında Kırgız edebiyatı yanında diğer Türk topluluklarının edebî metinleri ulusal edebiyat olarak okutulmamaktadır.

Ders kitapları, eğitim politikasının uygulama alanıdır. Kitaplar oluşturulurken program dâhilinde hareket edilir. Örneğin, Sovyet Döneminde "yasaklı eserler” dönemin ders kitaplarına konulmamışken Bă̆ımsızlık Döneminde bu eserler ders kitaplarında görülür. Sovyet Dönemi Kırgız yazılı edebiyatın öncülerinden Kasım Tinıstanov, Sıdık Karaçev ve Osmonaalı Sıdıkov Sovyet döneminde yasaklı edebiyatçllar arasındadır. Bağımsızlık dönemine kadar bu edebî kalemlerin eserlerinin konuşulması yasak olduğu ilgili çalışmalarda belirtilmiştir. Bă̆ımsızlık ile birlikte ders kitaplarında bu önemli kalemlerin tanıtıldığı ve değer verildiği görülür.

Dil ve edebiyat bir milletin kimliğidir. Toplum dil ile gelişerek köklerini gelecek nesillere taşır. Kırgız edebiyatı dersi ile öğrenci atalarının Sovyet döneminde yaşadıkları duyguları gözlemler, Sovyet öncesi dönemdeki önemli şairlerin eserlerini öğrenir ve kültürüne daha çok sahip çlkar. İncelenen ders kitaplarındaki edebî metinler konu bakımından değerlendirildiğinde ders kitaplarında daha çok ulusal değerlerin yer aldı̆̆ı gözlenmiştir.

Sonuç olarak, araştırma kapsamında incelenen ders kitaplarında millî bilinç oluşturmak için Kırgız edebiyatının önde gelen isimlerinin edebî eserleri okuma metinleri olarak seçilmiş ve ulusal ile evrensel değerler okuma metinleri yoluyla yeni nesillere aktarılmıştır.

\section{Kaynakça}

Abdıeva, R. (2017). Bağımsızlıklarını Kazandıktan Sonra Türk Cumhuriyetlerinin Dil Politikaları ve Türkiye ile Ortak Dil ve Ortak Alfabe Çalışmaları. TÜRKLAD, 1 (2), 184-119.

Açı, Önkaş, N. ve Günay, E. (2015). Ders Kitabı İnceleme Ölçütlerine Göre Türkçe Ders Kitaplarının Karşlaştırılması. International Journal of Languages Education, 3 (3), 365-378. 
Akimcan Kızı, B. (2008). Bağımsızlık Sonrası Kırgızistan Ortaöğretim Ders Kitaplarında Din Anlatımı, Sosyal Bilimler Enstitüsü, Yüksek Lisans Tezi, Ankara: Ankara Üniversitesi.

Aytaş, G. (2006). Edebî Türlerden Yararlanma. Milli Eğitim Dergisi, 169, 261-276.

Artıkbayev, K., Asanaliyev, K., Baygaziyev, S., İmanaliyev, K., İşekeyev, N., Muratov, A. (2013). Krrgız Adabiyat,, 11- Klass. Bişkek: Bilim Kompyuter.

Asanaliyev, K., Baygaziyev, S., Cigitov S. ve İmanaliyev, K. (2003). Kırgız Adabiyatı, 10- Klass. Bişkek: Mektep.

Aytaş, G. (2006). Edebî Türlerden Yararlanma. Milli Eğitim Dergisi, 169, 261-276.

Eskimen, A., D. (2016). Edebiyat (9-12) Ders Kitapları Üzerine Karşılaştırmalı Bir Araştırma: TürkiyeAmerika Birleşik Devletleri (Indiana Eyaleti) Örneği. Uşak Üniversitesi Sosyal Bilimler Dergisi, 38-61.

Kırgız Respublikasının Jalpı Bilim Berüüçü Uyumdarını 10-11 Klasstar Üçün "Kirgız Adabiyatı" Predmeti Boyunça Predmettik Standartı (Okutuu Kırgız Tilinde Jürgüzülgön Mektepter Üçün). Bişkek: 2018.

MEB. (2018). İlköğretim Tükçe DersiÖğretim Programı. Ankara: MEB Yayınları.

Yıldırım, A. ve Şimşek, H. (2013). Sosyal Bilimlerde Nitel Araştırma Yöntemleri. (9. bs.) Ankara: Seçkin Yayıncılık.

\section{Internet Kaynakları:}

2014-2020 Kırgız Cumhuriyeti Devlet Dil Gelişimi ve Dil Politikasının Geliştirilmesi Ulusal Programı, http://cbd.minjust.gov.kg/act/view/ky-kg/63683 (Erişim Tarihi: 30.06.2020)

http://cbd.minjust.gov.kg/act/view/ky-kg/98149 (Erişim Tarihi: 01.07.2020).

"Kırgızstan Elinin Assambleyası" https://assembly-kg.news/20-лет-ассамблее-народакыргызстана/ (Erişim Tarihi: 13.06.2020). 